\title{
Recent Spatial and Temporal Trends of Malaria in Korea
}

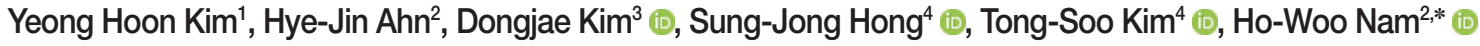 \\ ${ }^{1}$ Department of Ophthalmology, College of Medicine, Catholic University of Korea, Seoul 06591, Korea; '2Department of Parasitology, College of \\ Medicine, Catholic University of Korea, Seoul 06591, Korea; ${ }^{3}$ Department of Biomedicine Health Science, College of Medicine, The Catholic \\ University of Korea, Seoul 06591, Korea; ${ }^{4}$ Convergence Research Center for Insect Vectors, Incheon National University, Incheon 22012, Korea
}

\begin{abstract}
This study was done to provide an analytical overview on the latest malaria infection clusters by evaluating temporal trends during 2010-2019 in Korea. Incheon was the most likely cluster (MLC) for all cases of malaria during the total period. MLCs for P. falciparum, vivax, malariae, ovale, and clinically diagnosed malaria without parasitological confirmation were Jeollanam-do, Incheon, Gangwon-do, Gyeongsangnam-do, and Jeollabuk-do, respectively. Malaria was decreasing in most significant clusters, but Gwangju showed an increase for all cases of malaria, $P$. vivax and clinically diagnosed cases. Malaria overall, $P$. falciparum and $P$. vivax seem to be under control thanks to aggressive health measures. This study might provide a sound scientific basis for future control measures against malaria in Korea.
\end{abstract}

Key words: Malaria, health insurance review, assessment service, cluster, trend, spatial analysis, temporal analysis, SaTScan

\section{INTRODUCTION}

Diseases transmitted by arthropod vectors are major risk factors responsible for the global burden of infectious diseases [1]. Mosquito-borne diseases (MBDs) are important in this respect as they include malaria and several important arboviruses $[2,3]$. Aside from the high burden, they tend to emerge in new areas, and also re-emerge in regions known to have been eradicated.[2] Several factors such as globalization and climate changes are inducing shifts in communicable disease trends, and this is especially evident in MBDs $[1,4]$ as its incidence seems to show an increasing trend in parts of Korea.

Malaria is one of the oldest diseases, and its influence has probably been greater than that of any other infectious agents [5]. Caused by the Plasmodium species of protozoan parasites, malaria is a major public health burden worldwide [6]. P. falciparum is the most prevalent malaria parasite in Africa, and it is the greatest menace because of its high mortality rate [7]. P. vivax is less lethal than P. falciparum, but more prevalent in Korea [6]. It was eradicated from Korea late 1970s, but reemerged 1993 and continued prevalent despite the ongoing national eradication program [8]. P. malariae is a benign ma-

- Received 28 November 2021, revised 30 November 2021, accepted 30 November 2021.

*Corresponding author (howoo@catholic.ac.kr)

(c) 2021, Korean Society for Parasitology and Tropical Medicine

This is an Open Access article distributed under the terms of the Creative Commons Attribution Non-Commercial License (https://creativecommons.org/licenses/by-nc/4.0) which permits unrestricted non-commercial use, distribution, and reproduction in any medium, provided the original work is properly cited. laria with several distinct clinical features [9]. P. ovale make the infected RBC swollen and oval, the margin fimbriated, and stained pale, morphologically distinct from the others. In Korea, majority of the imported malaria cases were of $P$. falciparum (from Africa) and P. vivax (from Southeast Asia), whereas $P$. malariae and $P$. ovale cases were very rare [10].

Korea has a complete full health-coverage of its population. The clinical data from the Health Insurance Review and Assessment Service (HIRA) of Korea were used in this study, so that the whole Korean population is represented. Our study was performed to figure out spatial infection clusters and trends of the malaria, Plasmodium infections during recent 10 years in Korea.

\section{MATERIALS AND METHODS}

\section{Ethics statement}

This study was performed under the regulation of the IRB Committee of The Catholic University of Korea (No. MC20ZASE0155). This research adhered to the tenets of the Declaration of Helsinki.

\section{Data aquisition and definition}

The nationwide malaria cases for 10 years (2010-2019) from the 16 administrative districts in Korea were obtained from the Healthcare Bigdata Hub provided by the HIRA. (https://opendata.hira.or.kr/home.do. [cited 2020 October]) The HIRA classifies the Plasmodium infections as P. falciparum (B50), P. vivax 
(B51), P. malariae (B52), P. ovale, simian plasmodia (B53) and clinically diagnosed malaria without parasitological confirmation (B54).

The population data of 16 administrative divisions for the same period were obtained from the Korean Statistical Information Service (https://kosis.kr/index/index.do. [cited 2021 October]). The geographical locations of the cases were set to the latitude and longitude of administrative center as the search point since the case data were compiled by administrative district unit. The population and number of cases were summed up as accumulated counts and numbers for the total period to evaluate overall malaria status. Case numbers were adjusted for the respected district population (cases/1,000, 000) to facilitate comparison between the districts (Table 1).

Malaria disease according to individual classification were further evaluated by dividing the timeline into tertiles (20102012, 2013-2015, 2016-2019), and total period. The third tertile had 4 years of data to reflect more recent information, and to facilitate the evaluation of temporal characteristics.

Table 1. Population and malaria cases for 2010-2019 according to administrative district

\begin{tabular}{|c|c|c|c|c|c|c|c|}
\hline \multirow[b]{2}{*}{ Cluster (code) } & \multirow{2}{*}{$\begin{array}{l}\text { Cumulated } \\
\text { Population }\end{array}$} & \multicolumn{6}{|c|}{ Cases } \\
\hline & & P. falciparum & P. vivax & P. malariae & P. ovale & $\begin{array}{c}\text { Clicially } \\
\text { diagnosed }\end{array}$ & All cases \\
\hline Seoul (SE) & $100,309,373$ & 492 & 999 & 37 & 113 & 2,617 & 4,258 \\
\hline Busan (BU) & $35,042,646$ & 89 & 97 & 4 & 17 & 503 & 710 \\
\hline Daegu (DG) & $24,866,860$ & 56 & 67 & 1 & 10 & 352 & 486 \\
\hline Gwangju (GW) & $14,657,097$ & 51 & 42 & 4 & 32 & 357 & 486 \\
\hline Daejeon (DJ) & $15,108,648$ & 57 & 53 & 2 & 6 & 217 & 335 \\
\hline Ulsan (UL) & $11,546,517$ & 23 & 30 & 0 & 6 & 89 & 148 \\
\hline Gyeonggi-do (GY) & $124,839,896$ & 414 & 2,126 & 80 & 141 & 3,561 & 6,322 \\
\hline Gangwon-do (GA) & $15,426,610$ & 84 & 114 & 37 & 15 & 425 & 675 \\
\hline Chungcheongbuk-do (CB) & $15,798,992$ & 45 & 46 & 9 & 9 & 323 & 432 \\
\hline Jeollabuk-do (JB) & $18,605,718$ & 50 & 69 & 13 & 35 & 880 & 1,047 \\
\hline Jeollanam-do (JN) & $19,016,443$ & 271 & 43 & 5 & 14 & 608 & 941 \\
\hline Gyeongsangbuk-do (GB) & $26,925,299$ & 73 & 66 & 5 & 31 & 794 & 969 \\
\hline Gyeongsangnam-do (GN) & $33,458,210$ & 99 & 66 & 10 & 61 & 653 & 889 \\
\hline Jeju-do (JE) & $6,193,531$ & 4 & 11 & 4 & 4 & 195 & 218 \\
\hline \multirow[t]{2}{*}{ Total } & $511,567,491$ & 1,934 & 4,436 & 232 & 530 & 13,102 & 20,234 \\
\hline & & \multicolumn{6}{|c|}{ Adjusted cases* } \\
\hline Seoul (SE) & & 4.9 & 9.96 & 0.37 & 1.13 & 26.09 & 42.45 \\
\hline Busan (BU) & & 2.54 & 2.77 & 0.11 & 0.49 & 14.35 & 20.26 \\
\hline Daegu (DG) & & 2.25 & 2.69 & 0.04 & 0.40 & 14.16 & 19.54 \\
\hline Incheon (IN) & & 2.59 & 19.64 & 0.31 & 0.62 & 34.27 & 57.44 \\
\hline Gwangju (GW) & & 3.48 & 2.87 & 0.27 & 2.18 & 24.36 & 33.16 \\
\hline Gyeonggi-do (GY) & & 3.32 & 17.03 & 0.64 & 1.13 & 28.52 & 50.64 \\
\hline Gangwon-do (GA) & & 5.45 & 7.39 & 2.40 & 0.97 & 27.55 & 43.76 \\
\hline Chungcheongbuk-do (CB) & & 2.85 & 2.91 & 0.57 & 0.57 & 20.44 & 27.34 \\
\hline Chungcheongnam-do (CN) & & 2.45 & 1.87 & 0.58 & 0.86 & 25.75 & 31.50 \\
\hline Jeollabuk-do (JB) & & 2.69 & 3.71 & 0.70 & 1.88 & 47.3 & 56.27 \\
\hline Jeollanam-do (JN) & & 14.25 & 2.26 & 0.26 & 0.74 & 31.97 & 49.48 \\
\hline Gyeongsangbuk-do (GB) & & 2.71 & 2.45 & 0.19 & 1.15 & 29.49 & 35.99 \\
\hline Gyeongsangnam-do (GN) & & 2.96 & 1.97 & 0.30 & 1.82 & 19.52 & 26.57 \\
\hline Jeju-do (JE) & & 0.65 & 1.78 & 0.65 & 0.65 & 31.48 & 35.20 \\
\hline Total & & 59 & 85 & 8 & 16 & 397 & 565 \\
\hline
\end{tabular}

${ }^{*}$ Adjusted cumulated infection rate (cases/1,000,000). 


\section{Spatiotemporal statistical analyses}

Spatial scan analysis detects clusters with maximum likelihood ratio by creating a circular window on a map and scanning the study area by varying the window size. The window size determines a percentage of the population at risk within its boundaries [11]. Spatial scan statistic works best for detecting spatial clusters, and may be effective in the study of small numbered cases, such as novel or infrequent outbreaks [12, 13]. SaTScan (v10.0) [14] software was used to detect these clusters and evaluate their significance through simulation. The discrete Poisson model was used since the malaria case data were linked to their background population at risk.

Disease trend was determined through spatial variation in temporal trend analysis, by scanning for clusters with either increasing or decreasing rates. Data for $P$. malariae in Ulsan was missing and was adjusted for known relative risks according to the SaTScan software guide.

It is important to find an appropriate set value of cluster size because a large value could hide effect of small core clusters, while a small value could overlook the regional pattern of clusters [15]. Preliminary studies with 15 and 25\% spatial window sizes showed that the $15 \%$ window size was most effective in finding clusters. The present study selected this window size for statistical analyses.

Statistical significance of the clusters was calculated using the Monte Carlo simulations with an inference of 9,999 [16] and expressed as $P$-value. A significance level of alpha $<0.05$ was used as a standard. QGIS software (v3.16) was used to visualize cluster patterns on a map. The clusters and trends are shown in order of log likelihood ratio (LLR).

\section{RESULTS}

\section{General characteristics}

Gyeonggi-do had the highest population $(124,839,896)$ and highest number of cases (31.3\%) during the study period. After adjusting the case numbers for population, Incheon (57.4) and Jeollabuk-do (56.3) showed the highest rate of infection.

\section{Spatial clusters}

When considering for all cases of malaria, Incheon was the most likely cluster (MLC) with a relative risk (RR) and LLR of 1.49 and 109.579 , respectively, for the whole study period. The joint cluster of Jeollanam-do/Jeollabuk-do was next ( $\mathrm{RR}=1.37$,
$\mathrm{LLR}=82.628)$, followed by Jeollabuk-do $(\mathrm{RR}=1.45, \mathrm{LLR}=60$. 557), and Jeollanam-do $(\mathrm{RR}=1.26, \mathrm{LLR}=22.861)$ (Table 2). Gangwon-do was a significant cluster at the first tertile of 20102012, and Gwangju was also significant at the mid tertile of 2013-2015 (Fig. 1).

Among clusters detected for $P$. falciparum, Jeollanam-do was the MLC $(\mathrm{RR}=4.22$, $\mathrm{LLR}=171.545)$ during the whole period. The next likely cluster was Gangwon-do (RR=1.46, LLR=5.146) (Table 2). Jeollanam-do was a significant at all tertiles, while Gangwon-do (RR=1.46, LLR=5.146) was only significant at the earlier tertile (Fig. 2). Incheon was the $\mathrm{MLC}(\mathrm{RR}=2.45$, $L L R=159.540)$ for $P$. vivax during the whole period (Table 2), and also the only significant cluster at all tertiles (Fig. 3). The MLC for P. malariae was Gangwon-do (RR=5.96, LLR=33.013) during the whole period (Table 2). Gyeongsangnam-do was the MLC $(\mathrm{RR}=1.86, \mathrm{LLR}=8.853)$ for $P$. ovale during the whole period. Gwangiu was the second $(\mathrm{RR}=2.18, \mathrm{LLR}=7.316)$, and Jeollabuk-do was the third likely cluster during the whole period $(\mathrm{RR}=1.87, \mathrm{LLR}=5.398)$ (Table 2).

For clinically diagnosed malaria, Jeollabuk-do was the MLC $(\mathrm{RR}=1.91, \mathrm{LLR}=142.846)$ for the whole period, followed by Incheon $(\mathrm{RR}=1.37$, LLR=40.797), Jeju-do/Jeollanam-do $(\mathrm{RR}=$ 1.26, $\mathrm{LLR}=18.776)$ and Gyeongsangbuk-do $(\mathrm{RR}=1.16, \mathrm{LLR}=$ 7.973) (Table 2).

\section{Temporal trends}

Temporal trends analysis for the whole study period showed that malaria infection rate was decreasing in most clusters (Fig. 4) Gwangju showed an increasing rate for all cases of malaria $(+8.8 \%, \mathrm{LLR}=73.128)$, P. vivax $(+6.03 \%, \mathrm{LLR}=6.866)$ and clinically diagnosed cases $(+17.25 \%$, $L L R=85.970)$. P. falciparum showed decreasing rates in Jeollanam-do/Jeollabuk-do/ Jeju-do/Daejeon $(-4.70 \%$, LLR $=20.700)$ and Gyeongsangbukdo/Daegu/Chungcheongbuk-do $(-23.70 \%$, LLR=9.456) joint clusters. Other clusters detected by purely spatial analysis showed varying degrees of decreasing rates (Table 3 ).

\section{DISCUSSION}

The present study provides an analytical overview of the latest malaria status in Korea by determining disease clusters and evaluating temporal trends during 2010-2019.

Korea is a peninsula, but the northern border is a demilitarized zone (DMZ) and cut off from the rest of Asia by North Korea. The result is virtually an isolated island, and contact 
Table 2. Clusters detected malaria

\begin{tabular}{|c|c|c|c|c|c|c|}
\hline & District & Cases & Expected & Relative Risk & $\begin{array}{l}\text { Log Likelihood } \\
\text { Ratio }\end{array}$ & $P$-value \\
\hline \multicolumn{7}{|l|}{ All cases } \\
\hline \multirow[t]{3}{*}{ 2010-2012 } & Incheon & 694 & 471 & 1.52 & 49.274 & $<0.001$ \\
\hline & Jeollanam-do, Jeollabuk-do & 733 & 636 & 1.17 & 7.674 & 0.00 \\
\hline & Gangwon-do & 314 & 258 & 1.23 & 5.914 & 0.01 \\
\hline \multirow[t]{3}{*}{ 2013-2015 } & Incheon & 497 & 322 & 1.60 & 43.556 & $<0.001$ \\
\hline & Gyeongsangbuk-do & 406 & 300 & 1.38 & 17.984 & $<0.001$ \\
\hline & Gwangju & 202 & 164 & 1.24 & 4.342 & 0.04 \\
\hline \multirow[t]{4}{*}{ 2016-2019 } & Jeollanam-do, Jeollabuk-do & 823 & 438 & 2.02 & 147.836 & $<0.001$ \\
\hline & Jeollabuk-do & 438 & 216 & 2.11 & 91.604 & $<0.001$ \\
\hline & Jeollanam-do & 385 & 221 & 1.79 & 51.661 & $<0.001$ \\
\hline & Incheon & 470 & 346 & 1.39 & 21.285 & $<0.001$ \\
\hline \multirow[t]{4}{*}{ Total period } & Incheon & 1,661 & 1,144 & 1.49 & 109.579 & $<0.001$ \\
\hline & Jeollanam-do, Jeollabuk-do & 1,988 & 1,488 & 1.37 & 82.628 & $<0.001$ \\
\hline & Jeollabuk-do & 1,047 & 736 & 1.45 & 60.557 & $<0.001$ \\
\hline & Jeollanam-do & 941 & 752 & 1.26 & 22.861 & $<0.001$ \\
\hline \multicolumn{7}{|l|}{ P. falciparum } \\
\hline \multirow[t]{2}{*}{ 2010-2012 } & Jeollanam-do & 95 & 35 & 2.91 & 37.006 & $<0.001$ \\
\hline & Gangwon-do & 47 & 28 & 1.71 & 5.52 & 0.01 \\
\hline 2013-2015 & Jeollanam-do & 65 & 19 & 3.81 & 36.544 & $<0.001$ \\
\hline 2016-2019 & Jeollanam-do & 111 & 18 & 7.46 & 116.334 & $<0.001$ \\
\hline \multirow[t]{2}{*}{ Total period } & Jeollanam-do & 271 & 72 & 4.22 & 171.545 & $<0.001$ \\
\hline & Gangwon-do & 84 & 58 & 1.46 & 5.146 & 0.02 \\
\hline \multicolumn{7}{|l|}{ P. vivax } \\
\hline 2010-2012 & Incheon & 264 & 117 & 2.42 & 72.733 & $<0.001$ \\
\hline 2013-2015 & Incheon & 169 & 59 & 3.22 & 73.935 & $<0.001$ \\
\hline 2016-2019 & Incheon & 135 & 73 & 1.96 & 22.949 & $<0.001$ \\
\hline Total period & Incheon & 568 & 251 & 2.45 & 159.54 & $<0.001$ \\
\hline \multicolumn{7}{|l|}{ P. malariae } \\
\hline Total period & Gangwon-do & 37 & 7 & 5.96 & 33.013 & $<0.001$ \\
\hline \multicolumn{7}{|l|}{ P. ovale } \\
\hline \multirow[t]{3}{*}{ Total period } & Gyeongsangnam-do & 61 & 35 & 1.86 & 8.853 & $<0.001$ \\
\hline & Gwangju & 32 & 15 & 2.18 & 7.316 & 0.00 \\
\hline & Jeollabuk-do & 35 & 19 & 1.87 & 5.398 & 0.01 \\
\hline \multicolumn{7}{|c|}{ Clinically diagnosed malaria } \\
\hline \multirow[t]{4}{*}{ Total period } & Jeollabuk-do & 880 & 477 & 1.91 & 142.846 & $<0.001$ \\
\hline & Incheon & 991 & 741 & 1.37 & 40.797 & $<0.001$ \\
\hline & Jeju-do, Jeollanam-do & 803 & 646 & 1.26 & 18.776 & $<0.001$ \\
\hline & Gyeongsangbuk-do & 794 & 690 & 1.16 & 7.973 & 0.00 \\
\hline
\end{tabular}

*Decreasing order of Log Likelihood Ratio.

with the outside world is limited to air- and sea-routes. The western and southern parts have numerous islands that number around 5,000, and a fair number of them are inhabited. This means limited resources stretched over a large area with isolated populations, a potential health hazard for the related authorities.

In terms of climate, Korea is mostly located in the temperate zone, except for Jeju-do, but global warming has caused semitropical climate changes in the southern parts of the mainland.
These factors might have caused an influence in the increased rate of various infectious diseases.

With recent economic prosperity large numbers of Koreans are enjoying travelling, both domestic and international. And especially among the young generation, their interest has shifted from urban travel to seeking out nature as it is. Trekking, hiking, wildlife experiences, and related outdoor life have become the trend. This may also have an effect on the spread of malaria.

We included the data on clinically diagnosed malaria with- 

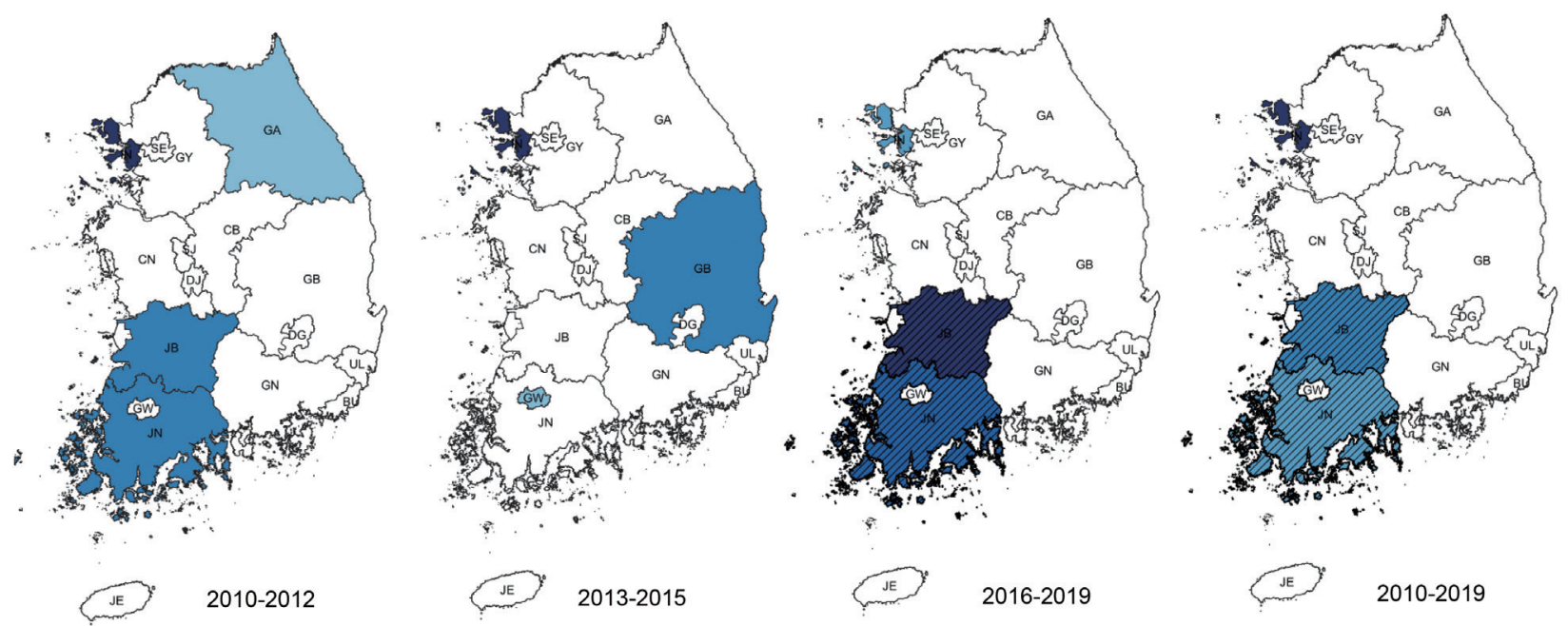

Fig. 1. Clusters detected for all cases of malaria. Area codes represent administrative districts of the Korean government. Light to dark blue gradient indicates increasing order of log likelihood ratio. Dashed lines represent a joint cluster.
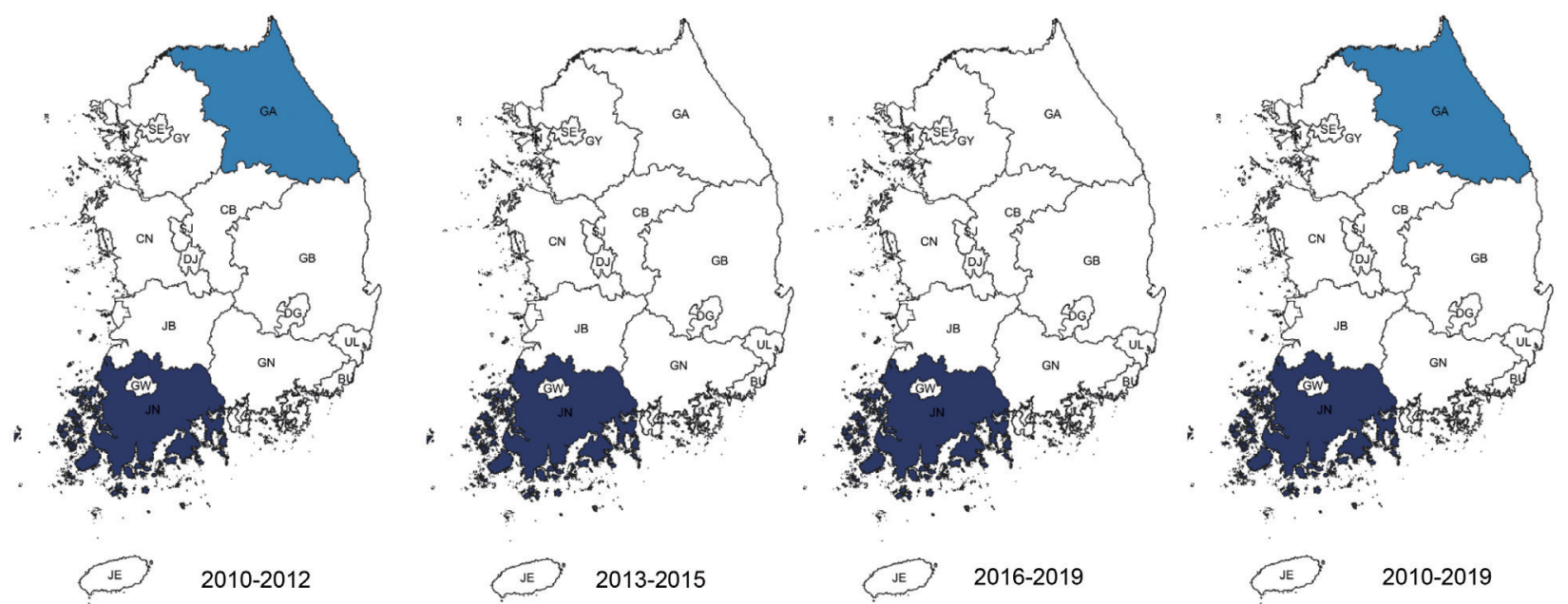

Fig. 2. Clusters detected for $P$. falciparum. Area codes represent administrative districts. Light to dark blue gradient indicates increasing order of log likelihood ratio.
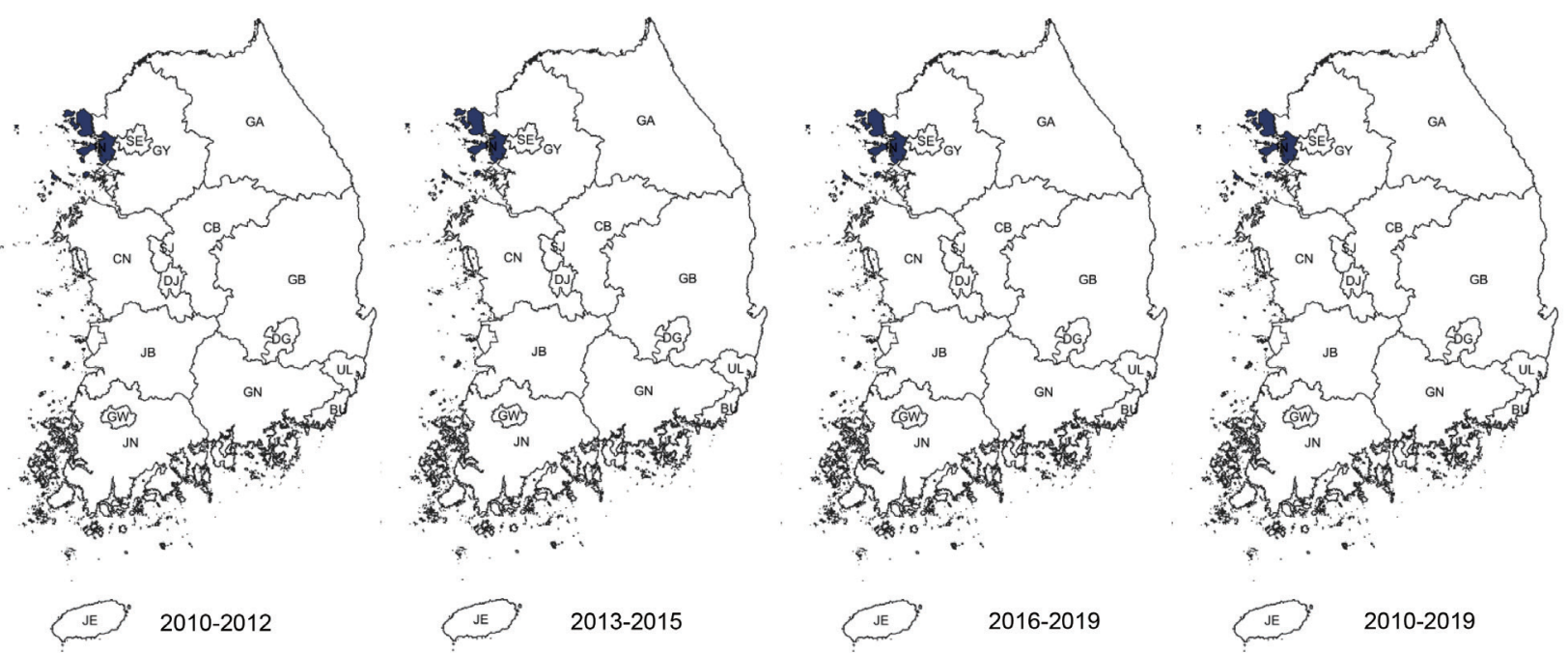

Fig. 3. Clusters detected for $P$. vivax. Area codes represent administrative districts. Incheon was the most likely cluster. 


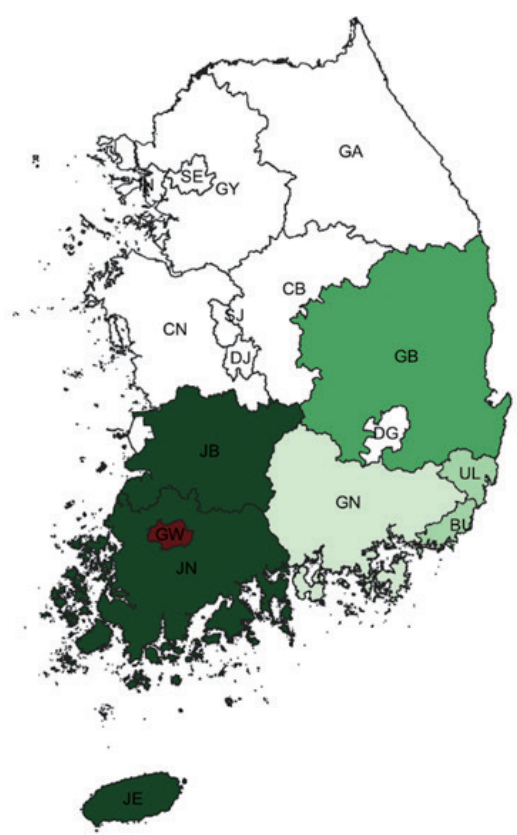

Total cases

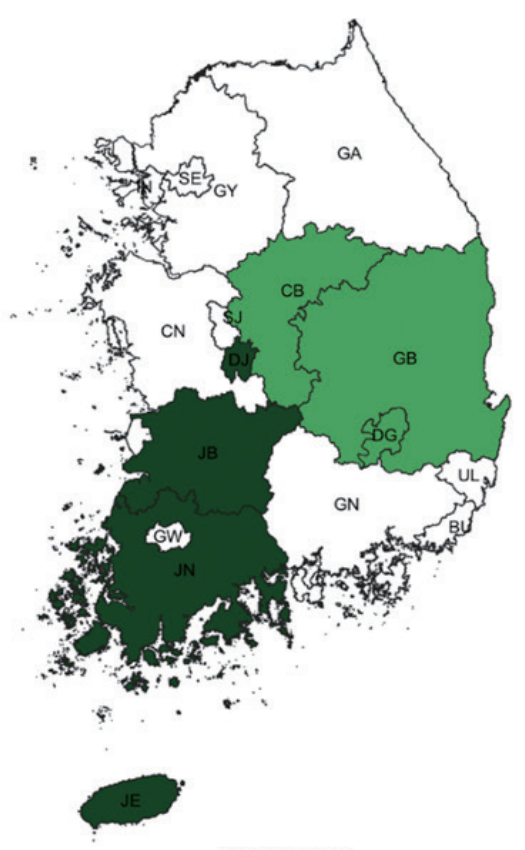

P. falciparum

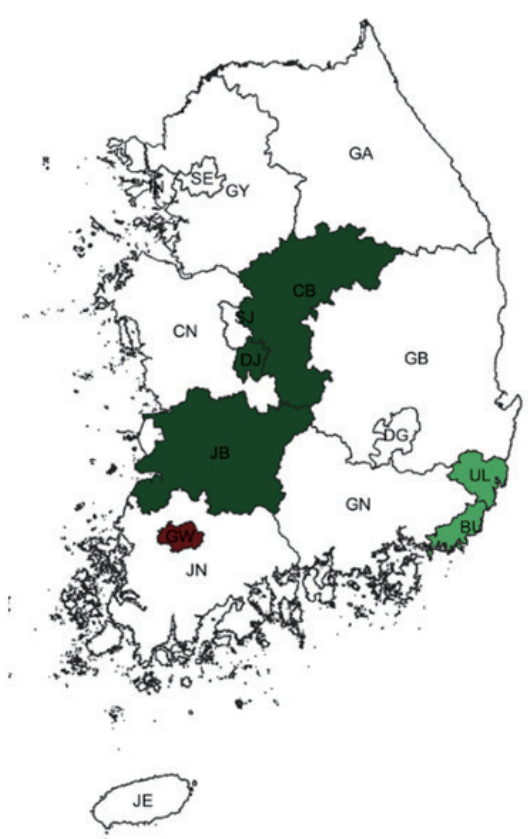

P. vivax

Fig. 4. Spatiotemporal trends of malaria. Area codes represent administrative districts. Green represents clusters that showed decreased rate over the period of 2010-2019. Light to dark green gradient indicates increasing order of log likelihood ratio. Red represents clusters that showed increase over the same period.

Table 3. Temporal trends of malaria

\begin{tabular}{|c|c|c|c|c|c|c|}
\hline Malaria & Districts & Cases & $\begin{array}{l}\text { Trend inside } \\
\text { cluster }\end{array}$ & $\begin{array}{l}\text { Trend outside } \\
\text { cluster }\end{array}$ & $\begin{array}{l}\text { Log Likelihood } \\
\text { Ratio }\end{array}$ & $P$-value \\
\hline \multirow[t]{5}{*}{ All cases } & Gwangju & 486 & 8.80 & -10.47 & 73.128 & $<0.001$ \\
\hline & Jeju-do, Jeollanam-do, Jeollabuk-do & 2,206 & -2.57 & -10.93 & 63.799 & $<0.001$ \\
\hline & Gyeongsangbuk-do & 969 & -19.70 & -9.56 & 45.922 & $<0.001$ \\
\hline & Ulsan, Busan & 858 & -15.23 & -9.83 & 11.593 & $<0.001$ \\
\hline & Gyeongsangnam-do & 889 & -6.58 & -10.19 & 5.260 & 0.03 \\
\hline \multirow[t]{2}{*}{ P. falciparum } & Jeollanam-do, Jeollabuk-do, Jeju-do, Daejeon & 382 & -4.70 & -16.47 & 20.700 & $<0.001$ \\
\hline & Gyeongsangbuk-do, Daegu, Chungcheongbuk-do & 193 & -23.70 & -13.15 & 9.456 & 0.00 \\
\hline \multirow[t]{3}{*}{ P. vivax } & Jeollabuk-do, Daejeon, Chungcheongbuk-do & 168 & -22.86 & -12.80 & 7.965 & 0.00 \\
\hline & Ulsan, Busan & 127 & -23.66 & -12.89 & 6.925 & 0.01 \\
\hline & Gwangju & 42 & 6.03 & -13.33 & 6.866 & 0.01 \\
\hline P. malariae & Jeollanam-do, Jeollabuk-do, Jeju-do, Daejeon & 24 & 22.14 & -6.27 & 5.741 & 0.02 \\
\hline P. ovale & Jeollabuk-do & 35 & 0.80 & -19.81 & 6.714 & 0.01 \\
\hline \multirow[t]{6}{*}{ Clinically diagnosed } & Gwangju & 357 & 17.25 & -8.78 & 85.97 & $<0.001$ \\
\hline & Jeju-do, Jeollanam-do, Jeollabuk-do & 1,683 & -0.50 & -9.25 & 50.545 & $<0.001$ \\
\hline & Gyeongsangbuk-do & 794 & -18.45 & -7.49 & 42.941 & $<0.001$ \\
\hline & Daejeon & 217 & -21.79 & -7.93 & 19.403 & $<0.001$ \\
\hline & Ulsan, Busan & 592 & -13.11 & -7.94 & 7.191 & 0.00 \\
\hline & Chungcheongbuk-do & 323 & -1.81 & -8.31 & 6.027 & 0.01 \\
\hline
\end{tabular}

*Trend inside/outside cluster denotes \% increase/decrease over the period of 2010-2019.

${ }^{* *}$ Decreasing order of Log Likelihood Ratio.

out parasitological confirmation. This was a point of debate among the authors. The purpose of this study was to determine the current status of malaria in Korea, so we decided to include it.

When all cases of malaria during the whole study period were evaluated, significant clusters were observed in the west- 
ern part of Korea, mainly Incheon and the Jeolla area (Jeollabuk-do and Jeollanam-do). Gangwon-do, and Gyeongsangbuk-do were clusters during the first tertile (2010-2012).Located in the western part of Korea, Incheon is the main access point for international travel and commerce, and its proximity with China has resulted in a large number of Chinese imigration. The outermost regions are also adjacent to North Korea. The Jeolla area is mainly an agricultural zone located in the west. Additionally, together with Incheon, fishery is also important in this area. Both are labor intensive, and with the Korean population declining and growing old, it has resulted in a large influx of foreigners, mainly from Southeast Asia, but also from Africa and South America.

Gangwon-do has a relatively small population spread over a large area. The DMZ is located in its northern part, which means an even smaller civilian population. Ironically, despite its name, this place is one of the most militarized area in the world, and generally off limits to civilians. The result is one of the most preserved natural habitats in the world abounding with wildlife. Because of its location between the two Koreas and the absence of humans, animals move freely into both countries. Apart from the preservation of nature that results in potential animal reservoirs of zoonosis, a large number of soldiers are stationed in this area. This has interesting consequences. Technically still at war, Korea has military conscription, so male citizens between the ages of 18 and 28 have to perform compulsory military service. A large number are also stationed in Incheon. After military service, these young men go back home, all throughout Korea. They might play a role in disease reservoir and spread of disease.

P. falciparum clusters were observed in Jeollanam-do and Gangwon-do. As mentioned above, Jeollanam-do is located in the southwestern part of Korea, and has an almost semi-tropical climate at times. Agriculture and fisheries require massive influx of foreign labor force, which might all be significant. Indigenous falciparum malaria has not been reported [7]. Gangwon-do was a cluster in the first tertile. This could have been caused by the large number of soldiers stationed in the DMZ. In 1979 the WHO officially certified that Korea was a malariafree country [18], but vivax malaria re-emerged in 1993 in a soldier. Massive efforts were enforced to contain the disease, and this might have inadvertently caused the decrease in $P$. falciparum.

Vivax malaria has been an endemic infectious disease in the Korea for a long time [7]. Although it has re-emerged, renewed eradication programs have been put in force. Our study shows that Incheon is a significant cluster. Most cases at the beginning of the vivax malaria outbreak occurred among soldiers stationed near the DMZ in the northern part of Gyeonggi and Gangwon-do, and among veterans who had been discharged. This suggested that North Korea might be a major reservoir of vivax malaria, and Incheon is also adjacent to North Korea. Another interesting point to consider it that the re-emerged $P$. vivax in Korea has genealogical origin in Southern China. As mentioned above, Incheon is major point of contact with China [19].

P. malariae causes the most benign form of malaria infection, and has several distinct clinical features [20]. It has been detected in the Greater Mekong Subregion (GMS) of Southeast Asia [21]. Foreign workers from this region can be seen frequently in Korea, and this population might have been reflected in the cluster found in our study. This region also happens to be a favorite destination for Korean travelers. A cluster was observed in Gangwon-do.

P. ovale occurs mainly in sub-Saharan Africa and islands of the western Pacific [22], and often presents as mixed infections with other Plasmodium species. The Gyeongsang area has a large population, and thus has major international airports that connect to the West Pacific countries, another favorite destination for Korean travelers. As a result, in contrast to the other Plasmodium species, a P. ovale cluster was observed in Gyeongsangnam-do. Gwangju Metropolitan City is located roughly at the geographic center of the Jeolla area, and as its name implies, is host to major medical resources, so that complicated cases from this area might have been referred to Gwangju, thus resulting in a cluster.

In the case of clinically diagnosed malaria without parasitological confirmation, the symptoms and signs might have been obvious enough to have been diagnosed without confirmation. Clusters were observed throughout the country, except for most major metropolitan cities (Seoul, Daejon, Daegu, Ulsan, Busan), Gyeonggi-do and the Chungcheong area. The major cities and Gyeonggi-do are far more industrialized and urbanized, with better access to medical resources. This may have helped in lowering the malaria risk.

On the other hand, while the Chungcheong area is situated in the middle of Korea, it tends to be isolated in some places, and its medical resource is far from satisfactory. Thus, its low rate of malaria is a paradox, but this might have been caused because its patients would simply just visit a medical facility in 
a nearby city. Being in the middle of everywhere, travelling is facilitated by extensive road and railway infrastructure. And being an inland area, global warming might have had a lesser impact.

Significant clusters with either increasing or decreasing rates of malaria were mainly located in the southern part of Korea. Evaluation for all of cases of malaria showed decreasing trends in the southern parts, except for Gwangju. The city might function as the main medical support system for the surrounding area, so complicated cases would all end up here, resulting in an increasing trend (8.8\%) compared to areas outside of the cluster (-10.47\%).

Clinically diagnosed cases showed a similar trend, with Gwangju showing an increase of $17.25 \%$ in comparison to a decrease of $-8.78 \%$ in other areas. General trends showed that these cases decreased initially, but increased again. This may have resulted in the significant increase observed in Gwangju. Despite being a major cause of malaria, $P$. falciparum showed a decreasing rate. Aggressive malaria containment measures seem to have been effective. P. vivax also showed a decreasing trend, but was increasing in Gwangju (6.03\% vs. -13.33\%). Its role as a health resources hub again seems to be responsible. Interestingly, the general trend of P. vivax showed that although cases were decreasing in number, the adjusted numbers were high and concentrated around Incheon, Gyeonggi-do and Seoul. This might potentially reflect the fact that aggressive anti-malaria health measures were effective in controlling vivax malaria elsewhere.

Although the cases are fewer in number, $P$. malariae showed an increasing trend in the Daejon/Jeolla area/Jeju-do joint cluster (22.14\% vs. $-6.27 \%)$, while P. ovale was increasing in Jeollabuk-do $(0.80 \%$ vs. $-19.81 \%)$. A climatic factor, such as higher average temperature or rainfall might have been possible during this period, with facilitated survival of the pathogens. Also, an increased influx of potential hosts from afflicted areas, both Korean and foreign, might have been responsible for this changing trend. These variants might occupy an ever more significant niche, and in the future, even surpass vivax and falciparum malaria.

In conclusion, after taking account of indigenous malaria with various health measures, global warming seems to be the factor most responsible for malaria in Korea as the southern regions are most affected.

\section{ACKNOWLEDGMENTS}

I dedicate this study to my late father Han Doo Kim, who has made me what I am today, and who with his intense curiosity for all things, taught me to strive for knowledge above all.

This study was supported by a research grant from the Korean Association of Health Promotion (No. 2015-01), Republic of Korea.

\section{CONFLICT OF INTEREST}

The authors declare no conflict of interest related to this study.

\section{REFERENCES}

1. Franklinos LHV, Jones KE, Redding DW, Abubakar I. The effect of global change on mosquito-borne disease. Lancet Infect Dis 2019; 19: 302-312. https://doi.org/10.1016/S1473-3099(19)30161-6

2. Huang YJS, Higgs S, Vanlandingham DL. Emergence and re-emergence of mosquito-borne arboviruses. Curr Opin Virol 2019; 34: 104-109 https://doi.org/10.1016/j.coviro.2019.01.001

3. Kilpatrick AM, Randolph SE. Drivers, dynamics, and control of emerging vector-borne zoonotic diseases. Lancet 2012; 380: 1946-1955. https://doi.org/10.1016/S0140-6736(12)61151-9

4. Bahk YY, Park SH, Kim-Jeon MD, Oh SS, Jung H, Jun H, Kim KA, Park JM, Ahn SK, Lee J, Choi EJ, Moon BS, Gong YW, Kwon MJ, Kim TS. Monitoring culicine mosquitoes (diptera: culicidae) as a vector of flavivirus in incheon metropolitan city and HwaseongSi, Gyeonggi-Do, Korea, during 2019. Korean J Parasitol 2020; 58: 551-558. https://doi.org/10.3347/kjp.2020.58.5.551

5. Carter R, Mendis KN. Evolutionary and historical aspects of the burden of malaria. Clin Microbiol Rev 2002; 15: 564-594. https:// doi.org/10.1128/cmr.15.4.564-594.2002

6. Lee SK, Hu F, Firdaus ER, Park JH, Han JH, Lee SE, Shin HI, Cho SH, Park WS, Lu F, Han ET. Surveillance on the vivax malaria in endemic areas in the Republic of Korea based on molecular and serological analyses. Korean J Parasitol 2020; 58: 609-617. https://doi.org/10.3347/kjp.2020.58.6.609

7. Bahk YY, Lee HW, Na BK, Kim J, Jin K, Hong YS, Kim TS. Epidemiological characteristics of re-emerging vivax malaria in the Republic of Korea (1993-2017). Korean J Parasitol 2018; 56: 531-543. https://doi.org/10.3347/kjp.2018.56.6.531

8. Chai JY. Re-emerging Plasmodium vivax malaria in the Republic of Korea. Korean J Parasitol 1999; 37: 129-143. https://doi.org/10. 3347/kjp.1999.37.3.129

9. Collins WE, Jeffery GM. Plasmodium malariae: parasite and disease. Clin Microbiol Rev 2007; 20: 579-592. https://doi.org/10.1128/ CMR.00027-07

10. Shin HI, Ku B, Kim YJ, Kim TY, Cho SH, Lee SE. Diagnosis and mo- 
lecular analysis on imported Plasmodium ovale curtisi and P. ovale wallikeri malaria cases from West and South Africa during 20132016. Korean J Parasitol 2020; 58: 61-65. https://doi.org/10.3347/ kjp.2020.58.1.61

11. Kulldorff M, Nagarwalla N. Spatial disease clusters: detection and inference. Stat Med 1995; 14: 799-810. https://doi.org/ https://doi.org/10.1002/sim.4780140809

12. Mathes RW, Lall R, Levin-Rector A, Sell J, Paladini M, Konty KJ, Olson D, Weiss D. Evaluating and implementing temporal, spatial, and spatio-temporal methods for outbreak detection in a local syndromic surveillance system. PLoS One 2017; 12: e0184419. https://doi.org/10.1371/journal.pone.0184419

13. Stelling J, Yih WK, Galas M, Kulldorff M, Pichel M, Terragno R, Tuduri E, Espetxe S, Binsztein N, O'Brien TF, Platt R. Automated use of WHONET and SaTScan to detect outbreaks of Shigella spp. using antimicrobial resistance phenotypes. Epidemiol Infect 2010; 138: 873-883. https://doi.org/10.1017/S0950268809990884

14. Kulldorff M. A spatial scan statistic. Commun Stat Theory Methods 1997; 26: 1481-1496. https://doi.org/10.1080/03610929708831995

15. Chen J, Roth RE, Naito AT, Lengerich EJ, MacEachren AM. Geovisual analytics to enhance spatial scan statistic interpretation: an analysis of U.S. cervical cancer mortality. Int J Health Geogr 2008; 7: 57. https://doi.org/10.1186/1476-072X-7-57

16. Azage M, Kumie A, Worku A, Bagtzoglou AC. Childhood diarrhea exhibits spatiotemporal variation in Northwest Ethiopia: a
SaTScan spatial statistical analysis. PLoS One 2015; 10: e0144690. https://doi.org/10.1371/journal.pone.0144690

17. Park SH, Jegal S, Ahn SK, Jung H, Lee J, Na BK, Hong SJ, Bahk YY, Kim TS. Diagnostic performance of three rapid diagnostic test kits for malaria parasite Plasmodium falciparum. Korean J Parasitol 2020; 58: 147-152. https://doi.org/10.3347/kjp.2020.58.2.147

18. Organization WH. Synopsis of the world malaria situation, 1979. Wkly Epidem Rec 1981; 56: 145-149. https://apps.who.int/iris/ handle/10665/223485

19. Iwagami M, Hwang SY, Fukumoto M, Hayakawa T, Tanabe K, Kim SH, Kho WG, Kano S. Geographical origin of Plasmodium vivax in the Republic of Korea: haplotype network analysis based on the parasite's mitochondrial genome. Malar J 2010; 9: 184. https://doi.org/10.1186/1475-2875-9-184

20. Collins WE, Jeffery GM. Plasmodium malariae: parasite and disease. Clin Microbiol Rev 2007; 20: 579-592. https://doi.org/10.1128/ CMR.00027-07

21. Li P, Zhao Z, Xing H, Li W, Zhu X, Cao Y, Yang Z, Sattabongkot J, Yan G, Fan Q, Cui L. Plasmodium malariae and Plasmodium ovale infections in the China-Myanmar border area. Malaria J 2016; 15: 557. https://doi.org/10.1186/s12936-016-1605-y

22. Kim G, Hong HL, Kim SY, Lee HR, Kim DG, Park S, Shin HS, Chin BS, Kim Y. Mixed infection with Plasmodium falciparum and Plasmodium ovale in a returned traveller: the first case in Korea. J Korean Med Sci 2019; 34: 23-23. https://doi.org/10.3346/jkms.2019.34.e23 
